\title{
Abordagem para identificação de oportunidades de projetos em organizações sociais: desenvolvimento e estudo de caso
}

\author{
Patrícia da Silveiraa*, José Luis Duarte Ribeiro ${ }^{\mathrm{b}}$, lstefani Carisio de Paula ${ }^{\mathrm{c}}$ \\ a*p_silveir@yahoo.com.br, UFRGS, Brasil \\ bribeiro@producao.ufrgs.br, UFRGS, Brasil \\ cistefani@producao.ufrgs.br, UFRGS, Brasil
}

\begin{abstract}
Resumo
Este artigo aborda os processos de iniciação da gestão de projetos, a fim de propor uma abordagem para identificação de oportunidades e definição do escopo preliminar de projetos no âmbito de organizações sociais. A proposta está estruturada em dez etapas agrupadas em quatro macroetapas: (i) planejamento, (ii) coleta de informações, (iii) identificação de oportunidades e (iv) concepção do escopo preliminar dos projetos. A abordagem foi aplicada em uma organização comunitária, como estudo de caso, gerando seis oportunidades de projetos. As conclusões revelaram que a abordagem apresentada oferece uma visão completa dos elementos a serem considerados na concepção de projetos voltados para organizações sociais e favorece o engajamento dos membros dessas organizações.
\end{abstract}

Palavras-chave

Gestão de projetos. Pesquisa de marketing. Gestão de mudanças. Organizações sociais.

\section{Introdução}

Em um momento em que as corporações governam o mundo, as disparidades de renda são elevadas, o meio ambiente está deteriorado e a liberdade é ameaçada, o crescimento de organizações sociais representa uma grande esperança para a humanidade (LERNER, 2000). Somando-se a essas questões a impotência do Estado para atender todas as demandas sociais, as organizações sociais surgem como alternativas para captar recursos e viabilizar a elaboração e implantação de projetos que possibilitem ações transformadoras no campo assistencial, cultural, ambiental e esportivo (TENÓRIO, 1998).

Segundo Pereira e Perez (2002), organizações sociais constituem um modelo de organização pública não estatal representada por associações civis orientadas para o atendimento do interesse público. As organizações sociais constituem uma inovação institucional, embora não representem uma nova figura jurídica, inserindo-se no marco legal vigente sob a forma de associações civis sem fins lucrativos, que constituem o terceiro setor.

0 termo terceiro setor dá, portanto, um significado às iniciativas privadas de utilidade pública com origem na sociedade civil. Salamon e Anheier (1992) definem o terceiro setor valendo-se de cinco atributos que distinguem estas organizações de outros tipos de instituições: (i) formalmente constituídas para assegurar a sua permanência por um período mínimo, (ii) estrutura básica não governamental, (iii) gestão própria, (iv) finalidade social (sem fins lucrativos) e (v) trabalho voluntário.

Dentro das organizações incluídas no terceiro setor, citam-se as ONGs (Organizações não governamentais), OSCIPs (Organizações da sociedade civil de interesse público), entidades filantrópicas e outras formas de associações civis sem fins lucrativos atuantes nas áreas de ensino, pesquisa, preservação do meio ambiente, cultura e saúde, além de lazer, esporte e religião (FALCON, 1999). 
Nos últimos dez anos, as organizações sociais assumiram grande parte das ações necessárias à diminuição da exclusão social no Brasil. Embora não façam parte do Estado, essas organizações se revestem de caráter público, uma vez que se dedicam a causas e problemas sociais (TENÓRIO, 1998).

Atualmente, cerca de 250 mil organizações sociais movimentam cifras que correspondem a 1,5\% do PIB nacional, sendo a grande maioria de cunho filantrópico. Essas organizações são geridas por empreendedores sociais, capazes de encontrar novos produtos sociais e promover a distribuição de seus benefícios ao maior número de pessoas no menor prazo possível (ASHOKA; McKINSEY, 2001).

De modo geral, apesar da relevância de suas propostas, as dificuldades enfrentadas pelas organizações sociais brasileiras estão diretamente relacionadas com a forma de gerenciamento dessas entidades, seja pela inexperiência de seus gestores, seja pela premência e amplitude dos problemas sociais que enfrentam. Nesse sentido, poucas vezes conseguem desenvolver projetos de longo prazo (TENÓRIO, 1998). Por outro lado, o empreendedorismo social é uma área de conhecimento emergente dentro do tema empreendedorismo e da literatura de marketing sem fins lucrativos, refletindo a necessidade de formalização e profissionalização da gestão dessas organizações (WEERAWARDENA; MORTB, 2006; DEES; EMERSON; ECONOMY, 2001).

0 mesmo esforço de profissionalização se observa em relação a projetos. Armani (2001) destaca o crescimento do número de organizações sociais que realizam suas ações e obtêm recursos através de projetos, assim como o crescimento do número de instituições que financiam projetos, oferecem capacitação e prestam assessoria na área social. A necessidade de financiamentos internacionais ou locais motiva as organizações sociais a estruturarem sua gestão financeira, condição importante para a sustentabilidade da organização. Esse contexto vem provocando a incorporação e adequação das técnicas e ferramentas de gerenciamento empresarial para as organizações sociais, visando tornarem-se competitivas (CRUZ; ESTRAVIZ, 2000).

0 nível de exigência geral quanto à qualidade da ação social está crescendo e, por isso, torna-se fundamental para as organizações que atuam nesse segmento conhecerem e utilizarem formas de elaborar, gerenciar e avaliar projetos. É importante que as organizações sociais se qualifiquem para se credenciarem como sujeitos sociopolíticos na sociedade, o que é fator fundamental do desenvolvimento social e democrático de qualquer país (ARMANI, 2001).
As organizações sociais precisam identificar oportunidades de atuação na sociedade (pesquisa de mercado), empreender projetos (gestão de projetos) e conduzir processos de transformação social (gestão de mudanças), mas nem sempre possuem competências para desenvolver de forma sistemática essas tarefas. Assim, o referencial teórico deste artigo aborda esses três tópicos, os quais serviram de base para o cumprimento dos objetivos principais deste estudo e que podem ser resumidos como: propor e aplicar uma abordagem que sistematize a identificação de oportunidades e elaboração do escopo preliminar de projetos no âmbito das organizações sociais.

Este artigo está organizado conforme segue. A seção 2 apresenta o referencial teórico, contemplando os três temas de pesquisa. A seção 3 contém a abordagem proposta, enquanto a seção 4 relata e discute um estudo aplicando a abordagem. A seção 5 apresenta as conclusões do trabalho.

\section{Referencial teórico}

Os temas abordados neste referencial teórico são: gestão da mudança, gestão de projetos e pesquisa de mercado, que são considerados relevantes visto que a profissionalização e formalização da gestão de processos e projetos nas organizações podem ter como restrição a não cooperação dos colaboradores, através da resistência à mudança. Por essa razão, as modificações dos processos devem ser realizadas de forma organizada e em etapas, minimizando o impacto das mudanças sobre as pessoas e vice-versa. 0 tema pesquisa de mercado, por sua vez, está incluído porque este artigo concentra-se na fase da iniciação de projetos, mais especificamente, na identificação de oportunidades de projetos. A pesquisa de mercado constitui-se em ferramenta estruturada que auxilia as equipes de projeto a conduzirem o levantamento e análise de necessidades e demandas da sociedade, durante a iniciação de projetos.

\subsection{Gestão da mudança}

Define-se mudança como a alteração de um estado ou situação anterior para um estado ou situação futura que represente uma modificação significativa, ocorrendo por razões planejadas ou inesperadas (BARTOLI; HERMEL, 2004). A finalidade da mudança dentro de uma organização é adotar um processo inovador na dinâmica de trabalho, através de um projeto que vise a melhoria das potencialidades individuais e coletivas. Além disso, as pessoas devem compreender, assimilar e adotar uma nova postura, de modo que a mudança possa se concretizar. 
De acordo com Tzortzopoulos (2004), as mudanças em produtos, processos e serviços podem ser de caráter incremental (melhorias contínuas) ou inovador (melhoria radical). Elas podem envolver otimizações de projeto, de processo, detecção de defeitos, reclamações, adaptação dos produtos a novas condições, redução de custos e melhoria da qualidade dos produtos já existentes, entre outras. Em relação à mudança organizacional, Megginson (1986) distingue dois tipos: as reativas ou evolucionárias e as planejadas ou proativas. Mudanças evolucionárias seriam forçadas por algum problema ou crise que já afeta o desempenho da empresa. Normalmente são compreendidas por melhorias incrementais de menor impacto. Os problemas são resolvidos à medida que surgem e a mudança ocorre depois que se verificou a existência do problema e seus defeitos. As mudanças planejadas, por sua vez, são decorrentes da identificação do problema antes de ele surgir, por essa razão é resultado de uma postura administrativa proativa. Nesse caso, a empresa estabelece um novo curso em vez de corrigir o atual.

Independente do conceito de mudança, as mesmas deveriam ser respaldadas por estratégias claramente definidas e o processo de mudança deveria ser gerenciado. A definição de um método estruturado pode facilitar a realização da mudança. Além da iniciativa de buscar novas necessidades de mudanças, é necessário encontrar um modo de implementá-las de forma eficaz. As empresas fracassam na realização de seus projetos de mudança por não adotarem um método de gestão de mudança ou por não seguirem todas as etapas estabelecidas no método (KOTTER, 2005; JESTON; NELIS, 2008).

Um método de gestão de projetos pode oferecer estrutura para a sistematização da mudança em uma organização, entretanto, outros elementos, como comunicação, motivação, cultura organizacional e alinhamento estratégico, devem ser considerados para o sucesso do projeto de mudança e são comentados a seguir.

Promover uma comunicação oportuna, constante e transparente com os diferentes níveis hierárquicos da organização permite às pessoas a compreensão e integração ao processo de mudanças (JONES; CALDERONE; AGUIRRE, 2004). Impedir a participação das pessoas que deverão implantar a mudança, por melhor que seja o plano, fatalmente irá conduzir a resultados que não corresponderão às expectativas (DUCK, 1993).

Mandelli et al. (2003) comentam que as pessoas comumente apresentam resistência a mudanças e, portanto, devem ser mobilizadas para elas. Um dos maiores desafios da mudança é instigar as pessoas para um projeto de transformação. Jones, Calderone e Aguirre (2004) sugerem que sejam articuladas justificativas formais para a mudança, personalizadas para os vários tipos de públicos internos através de: análise da realidade, demonstração de viabilidade e roteiro para orientação comportamental. Essas justificativas fazem parte do trabalho de motivação. Kotter (1998) afirma que a energia para desencadear um processo de mudança torna-se suficiente quando cerca de 75\% da gerência de uma organização estão convencidos de que os negócios não podem continuar como estão.

Outro elemento mencionado na literatura é a influência da cultura organizacional. Em um primeiro momento da mudança deve ocorrer um esforço de avaliação do cenário cultural da organização. Deve-se avaliar se a organização está efetivamente preparada para a mudança, quais são os problemas mais sérios, os principais conflitos, os fatores que compõem e influenciam as fontes de liderança e resistência, os valores essenciais, as crenças, os comportamentos e as percepções (JONES; CALDERONE; AGUIRRE, 2004).

As mudanças devem estar alinhadas com os objetivos da organização. 0 desenho da mudança deve propiciar a sincronia das ações e esforços em direção à realização de uma estratégia comum, atravessando processos, estruturas, pessoas e a própria cultura (MANDELLl et al., 2003). Para influenciar as massas é preciso atingir cada componente, individualmente (COVEY, 2002; JONES; CALDERONE; AGUIRRE, 2004). Os fatores que definem as capacidades e incapacidades de uma organização evoluem ao longo do tempo, à medida que a empresa cresce. Cabe ao gerente avaliar se esses fatores estão adequados aos novos valores da organização. Muitas organizações desconhecem suas capacidades e tomam decisões inadequadas ou, ainda, cometem o erro de não possuir valores definidos que direcionem as decisões (CHRISTENSEN; OVERDORF, 2000).

Por outro lado, as mudanças são conduzidas e sustentadas pelas ações das pessoas. Um procedimento de seleção e contratação deve levar em consideração as competências e habilidades necessárias para as funções da organização. As decisões sobre as pessoas que ocuparão as posições na nova estrutura organizacional, por exemplo, poderão definir o sucesso ou o insucesso de um programa de mudanças. Investir tempo nessa etapa, não subestimar relações informais, mapear o equilíbrio do poder atual e pretendido, reagir com dureza e objetividade e exigir o cumprimento dos acordos estabelecidos são algumas das recomendações sugeridas para esta etapa (MANDELLl et al., 2003).

Kotter (1998) afirma que gerenciar mudanças consiste, basicamente, em tratar de mantê-las sob controle: assegurar-se de que os esforços sejam feitos dentro de prazos pré-determinados e que 
compromissos e promessas sejam cumpridos. Para Duck (1993), a gestão de mudanças exige, ainda, que a liderança administre e oriente as conexões emocionais presentes durante a transformação. Bossidy (2005) complementa afirmando que, por um lado, durante as etapas executivas, quanto maior a interação, mais rápidas e efetivas são as respostas e maiores são as chances de redirecionar o processo. Por outro lado, a sistematização da mudança exige um método e pode ser entendida e tratada como um projeto.

\subsection{Gestão de projetos}

Segundo o guia Project Management Body of Knowledge (PMBoK) (PROJECT..., 2008), um projeto pode ser definido como um esforço com datas de início e término definidas, empreendido para criar produtos, serviços ou resultados singulares. Os projetos também podem, com frequência, sofrer impactos sociais, econômicos e ambientais, intencionais ou não, com durações mais longas que as dos próprios projetos. Segundo Casarotto Filho (1995), o projeto denomina o estudo técnico, econômico e financeiro de um empreendimento. Os parâmetros de um projeto, que conduzem à sua execução, devem compreender um estudo de viabilidade cujo grau de profundidade é definido segundo sua dimensão e devem contemplar elementos como: suporte científico, recursos físicos, humanos e financeiros, políticas e prazos.

Segundo Kerzner (2002), empresas que optam por utilizar metodologias de gestão de projetos percebem, em seguida, que o potencial dos benefícios decorrentes é maior do que o imaginado inicialmente. Keelling (2002) destaca duas características que facilitam a efetivação dos resultados esperados: os gerentes podem planejar alternativas para que as etapas dos projetos não sejam afetadas com as flutuações de mercado e podem promover a motivação, a moral e o desenvolvimento pessoal dos membros das equipes envolvidas.

Os métodos de gestão de projetos podem ser categorizados em pelo menos três grupos. 0 primeiro grupo seria relativo a métodos específicos, como os métodos de desenvolvimento de produto, expressos em seus modelos referenciais como aqueles propostos por: Prasad (1997), Crawford e Benedetto (2000), Rozenfeld et al. (2006), Romano (2003) e Paula e Ribeiro (2007), entre outros. São métodos propostos para o gerenciamento de projetos de produto e, geralmente, possuem um enfoque abrangente $\mathrm{e}$ gerencial da área à qual o produto pertence. Uma segunda categoria de métodos de gestão de projetos seria a daqueles destinados a situações nas quais as mudanças de escopo são muito frequentes, como no desenvolvimento de sistemas e softwares. São denominados métodos ágeis, tendo como exemplos o Extreme Programming (XP), o método Scrum e o Crystal Methodology (CHARVAT, 2003). Por fim, existem métodos de gestão de projetos desenhados para situações nas quais as mudanças de escopo são menos intensas, tornando o seu controle viável e documentável. Nessa última categoria, é comum que as etapas do método de gestão do projeto sejam organizadas a partir dos processos de iniciação, planejamento, execução, controle e encerramento e que ele contemple uma quantidade de padrões documentais como atas, formulários de project charter, formulários de gestão de riscos, de gestão de escopo, entre outros. Exemplo de método suportado pelo ciclo de vida de gestão de projetos é o Methodware ${ }^{\circledR}$ (XAVIER et al, 2005), que pode ser adotado por organizações que realizem projetos nos quais o grau de inovação seja de moderado a baixo, ou que não considerem grandes variações de escopo ao longo do mesmo.

0 ciclo de vida dos projetos contempla os processos: iniciação, planejamento, execução, monitoramento e controle e encerramento. Neste artigo será dada ênfase aos processos de iniciação. Os processos de iniciação permitem a declaração e entendimento do escopo do projeto e a boa condução desse processo pode facilitar o bom andamento das etapas subsequentes (XAVIER, 2005). Na verdade, a iniciação do projeto tem forte relação com a gestão do portfólio de projetos da empresa e os principais resultados desse processo são: propostas de projetos aprovadas, escopo dessas propostas declarado e gerentes de projetos indicados para conduzir os processos de planejamento, execução, controle e encerramento junto a suas equipes.

Dentre os documentos do processo de iniciação se encontram o termo de abertura e a declaração do escopo preliminar do projeto a ser desenvolvido. Nesses documentos são designados os gerentes e as equipes e são documentadas as premissas e as restrições iniciais para a aprovação dos projetos, para que sejam oficialmente autorizados (PROJECT..., 2008; VALERIANO, 2001).

0 termo de abertura (ou project charter) é um documento que autoriza formalmente o projeto. A declaração do escopo preliminar do projeto produz uma definição preliminar de alto nível do termo de abertura do projeto, abordando e documentando os requisitos do projeto e da entrega, os requisitos do produto, os limites do projeto, os métodos de aceitação e o controle de alto nível do escopo (XAVIER et al, 2005; PROJECT..., 2008; VERZUH, 2000). Através do detalhamento da declaração do escopo preliminar, ocorre a validação do escopo do projeto para cada fase, incluindo objetivos, justificativas, premissas, restrições, orçamento preliminar, informações de 
mercado, necessidades, cronograma preliminar, entre outros (PROJECT..., 2008).

Nas fases subsequentes do projeto são desenvolvidas validações adicionais do escopo do projeto em relação a essa fase. A repetição dos processos de iniciação em cada fase subsequente também permite que o projeto seja interrompido se a necessidade de negócios não mais existir ou se o projeto for considerado incapaz de satisfazê-la (PROJECT..., 2008).

Em geral, o envolvimento dos clientes e de outras partes interessadas durante a iniciação aumenta a probabilidade de propriedade compartilhada, aceitação da entrega e satisfação do cliente e de outras partes interessadas. Essa aceitação é essencial para o sucesso do projeto (PROJECT..., 2008).

\subsection{Pesquisa de marketing}

A American Marketing Association (AMA) aprovou a seguinte definição para pesquisa de marketing: trata-se de uma função organizacional que visa criar, comunicar e entregar o valor aos clientes, além de controlar o relacionamento de maneira que beneficie a organização e as partes interessadas (AMERICAN..., 2007).

Conforme Miorando (2005), a classificação dos tipos de pesquisa de marketing detalha os procedimentos necessários para a obtenção de informações segundo abordagens passíveis de serem adotadas para resolver os problemas de uma pesquisa. Mattar (1996) considera, primeiramente, o objetivo e o grau afetos ao problema de pesquisa. Após, verifica a natureza do relacionamento entre as variáveis contempladas, resultando na classificação: a) pesquisas exploratórias, b) pesquisas conclusivas descritivas e c) pesquisas conclusivas causais.

A pesquisa exploratória é relevante em situações em que o pesquisador não dispõe de dados suficientes para prosseguir com o projeto de pesquisa. Entre os métodos para realização da pesquisa exploratória citam-se: (i) levantamento de dados secundários, (ii) entrevistas em profundidade, (iii) pesquisa piloto, (iv) pesquisas por grupos focados, (v) estudos de caso selecionados e (vi) observações informais (SAMARA; BARROS, 2002; AAKER; KUMAR; DAY, 2001; MATTAR, 1996).

As pesquisas conclusivas descritivas procuram descrever situações de mercado através da análise de dados primários. Podem ser (i) quantitativos ou (ii) qualitativos. Estudos quantitativos são realizados a partir da elaboração de amostras da população e análise das informações desses grupos através de extrapolação e interpretação dos resultados. Estudos qualitativos são realizados a partir de entrevistas individuais ou discussões de grupos e buscam caracterizar as amostras analisadas (SAMARA; BARROS, 2002).

As pesquisas conclusivas causais, segundo Mattar (1996), apóiam-se na causação determinística, na qual se espera que todo acontecimento (causa) provoque outro acontecimento (efeito). Uma das formas utilizadas em marketing para pesquisar as relações de causa e efeito consiste no uso de projetos de experimentos, que podem ser realizados em laboratório e em campo.

Após a coleta dos dados da pesquisa, os mesmos precisam ser analisados e, antes disso, passar por uma preparação por meio da utilização de técnicas estatísticas. As principais técnicas de preparação são (i) edição, (ii) codificação e (iii) ajuste estatístico (AAKER; KUMAR; DAY, 2001).

\section{Abordagem proposta}

Quanto à caracterização da pesquisa, o método utilizado neste trabalho pode ser classificado como pesquisa aplicada, orientada à geração de conhecimentos dirigidos à solução de problemas específicos, conforme critérios propostos por Silva e Menezes (2000). No que diz respeito à abordagem: descrição de etapas, técnicas e ferramentas utilizadas para atingir os objetivos, o mesmo classifica-se como pesquisa qualitativa. A pesquisa trabalha principalmente com dados essencialmente qualitativos, depoimentos, análises de textos, comparações e abordagens não numéricas. Contudo, também foram empregados procedimentos quantitativos em etapas determinadas da abordagem proposta.

Analisando os objetivos e procedimentos, a abordagem para identificação de oportunidades de projetos em organizações sociais, descrita nesta seção, foi desenvolvida seguindo os preceitos da pesquisa-ação. Conforme Thiollent (1997), a pesquisa-ação é um tipo de pesquisa que é concebida e realizada em estreita associação com uma ação ou com a resolução de um problema coletivo, onde os pesquisadores e os participantes do problema estão envolvidos de modo cooperativo ou participativo.

Inicialmente, as etapas para planejamento e elaboração de projetos foram extraídas da literatura, apoiando-se principalmente nas obras de Xavier (2005), Xavier et al. (2005) Project Management Institute (2008) e Valeriano (2001) e Verzuh (2000). A seguir, as etapas foram utilizadas em campo, junto a uma organização social que atua em diversos segmentos. 0 aprendizado prático levou à revisão do conjunto de etapas e do conteúdo de cada etapa, conduzindo a versão final da abordagem proposta. Por questões de clareza, neste artigo é apresentada diretamente 
a versão final da abordagem proposta, seguido de sua aplicação prática.

A abordagem proposta segue a premissa de que, a partir da identificação de elementos da identidade da organização e de suas dificuldades e aspirações, podem-se levantar oportunidades, as quais, através de ações concretas, podem geram o escopo preliminar de projetos. A estrutura da abordagem proposta está apresentada no Quadro 1.

\subsection{Planejamento}

A primeira etapa objetiva a constituição das equipes de trabalho, responsáveis pelo planejamento e pela condução das demais etapas da abordagem. Recomendam-se a constituição de duas equipes, compostas por dois níveis de atuação: (i) planejamento e gestão e (ii) operação, denominadas: conselho gestor e equipe técnica, respectivamente. De modo geral, o conselho gestor responsabiliza-se por atividades que envolvem decisões estratégicas e a equipe técnica, por tarefas operacionais.

Após, ocorre o detalhamento das etapas, que consiste na identificação, seleção e descrição das atividades adotadas pela organização para condução das etapas da abordagem. Trata-se da definição das atividades do empreendimento que vão conduzir às propostas de projetos.

A identificação das alternativas deve levar em conta as características da organização e o detalhamento, que incide na descrição dos procedimentos para realização das atividades selecionadas, devem contemplar, fundamentalmente, objetivos, público-alvo, métodos, prazos e recursos.

Um dos aspectos mais importantes do planejamento refere-se à definição de prazos para conclusão das etapas. Além de conferir credibilidade à condução

Quadro 1. Estrutura da abordagem proposta.

\begin{tabular}{|c|c|c|}
\hline & Macroetapas & Etapas \\
\hline \multirow{3}{*}{$1^{\mathrm{a}}$} & \multirow{3}{*}{ Planejamento } & 1. Constituição das equipes de trabalho \\
\hline & & 2. Detalhamento das etapas \\
\hline & & 3. Definição dos prazos \\
\hline \multirow[t]{2}{*}{$2^{\mathrm{a}}$} & \multirow{2}{*}{$\begin{array}{l}\text { Coleta de } \\
\text { informações }\end{array}$} & $\begin{array}{l}\text { 4. Desenvolvimento e aplicação dos } \\
\text { instrumentos de coleta de informação }\end{array}$ \\
\hline & & 5. Tabulação das informações \\
\hline \multirow[b]{2}{*}{$3^{\mathrm{a}}$} & \multirow{2}{*}{$\begin{array}{l}\text { ldentificação de } \\
\text { oportunidades }\end{array}$} & 6. Análise dos blocos de oportunidade \\
\hline & & $\begin{array}{l}\text { 7. Priorização dos pré-projetos (project } \\
\text { charter) }\end{array}$ \\
\hline \multirow{3}{*}{$4^{\mathrm{a}}$} & \multirow{3}{*}{$\begin{array}{l}\text { Concepção de } \\
\text { projetos }\end{array}$} & $\begin{array}{l}\text { 8. Redação da declaração do escopo } \\
\text { preliminar dos projetos }\end{array}$ \\
\hline & & $\begin{array}{l}\text { 9. Aprovação da declaração do escopo } \\
\text { preliminar dos projetos }\end{array}$ \\
\hline & & $\begin{array}{l}\text { 10. Divulgação da declaração do escopo } \\
\text { preliminar dos projetos }\end{array}$ \\
\hline
\end{tabular}

do método, garante que atividades predecessoras e sucessoras sejam convenientemente sequenciadas. Armani (2001) lembra que é com base na definição precisa das ações que se pratica o cálculo dos custos do projeto e a definição de cronogramas.

Dependendo do porte e da complexidade da organização, a programação das etapas pode exigir a utilização de recursos para monitoramento da execução das tarefas. Uma alternativa pode ser a utilização do diagrama de setas, que pode ser definido como uma ferramenta para planejar o cronograma mais conveniente à execução de um trabalho, permitindo seu monitoramento e o das tarefas correlacionadas e garantindo o término do trabalho no tempo previsto (INSTITUTO..., 2007).

\subsection{Coleta de informações}

$\mathrm{Na}$ segunda macroetapa, inicia-se a operacionalização das atividades planejadas. Primeiramente, os instrumentos de coleta de informações são desenvolvidos e aplicados; após, as informações coletadas são tabuladas. Entre os instrumentos de coleta de informação adequados ao propósito desta proposta, citam-se: (i) análises de documentos, (ii) caixas de sugestões, (iii) brainstorming, (iv) questionários aplicados, (v) entrevistas em profundidade e (vi) grupos focados.

A tabulação consiste na organização das informações coletadas na etapa anterior para serem utilizadas na terceira macroetapa - de identificação de oportunidades. Durante a tabulação, as informações devem ser classificadas em blocos comuns. Além disso, deve ocorrer a seleção e categorização das informações, envolvendo: padronização dos termos utilizados por diferentes segmentos, eliminação de redundâncias e desdobramento de informações complexas em itens simples.

\subsection{Identificação de oportunidades}

Na terceira macroetapa da abordagem, ocorre a análise dos blocos de oportunidades e a priorização dos pré-projetos. Os pré-projetos constituem os project charters, ou seja, documentos que reúnem informações sobre o negócio que o projeto está incumbido de tratar e descrevem o respectivo produto.

Neste momento, os blocos de oportunidades gerados na etapa anterior passam por análise técnica, conduzindo à identificação de pré-projetos. Após, os pré-projetos são priorizados para serem encaminhados à última macroetapa - de concepção do escopo preliminar dos projetos. 
Os três métodos para condução da análise dos blocos de oportunidades recomendados por esta pesquisa são: (i) análise de conteúdo, (ii) diagrama de afinidade e (iii) seminário. Para a priorização dos pré-projetos, os possíveis métodos contemplados nesta pesquisa são: (i) matriz de priorização, (ii) método AHP, (iii) matriz de classificação de portfólios e (iv) plebiscito.

Outros métodos podem ser encontrados na literatura e desenvolvidos pelas organizações durante a aplicação da abordagem. A decisão fica a critério das equipes, na etapa de planejamento.

\subsection{Concepção de projetos}

Após a priorização, os pré-projetos (project charters) devem ser detalhados, gerando declarações do escopo preliminar, contemplando as diretrizes para o planejamento do projeto propriamente dito. As etapas da concepção de projetos contemplam a redação, aprovação e divulgação das declarações para os membros da organização.

Mais informações sobre o escopo preliminar podem ser encontradas no referencial teórico deste artigo. Tecnicamente, o trabalho de elaboração do escopo preliminar é importantíssimo, pois detalha o que, quando, por quem e como serão realizados os projetos, quais são as etapas a serem vencidas, como será viabilizado política e financeiramente e como serão geridos e avaliados.

De modo geral, a redação das declarações do escopo preliminar dos projetos contempla o desenvolvimento da estrutura dos formulários de redação de projetos e seus preenchimentos. A responsabilidade de conduzir essas atividades cabe à equipe técnica. Ao conselho gestor, cabe selecionar os participantes para a atividade, conforme características indicadas pela equipe técnica.

O Quadro 2 apresenta um resumo geral da abordagem, contemplando as quatro macroetapas e as dez etapas, as alternativas de atividades para condução das etapas, as funções das equipes técnica e gestora e os resultados esperados.

\section{Estudo aplicado}

Esta seção apresenta o estudo de aplicação da abordagem proposta. Através de um contrato firmado entre a Federação lsraelita do Rio Grande do Sul (FIRGS) e a Fundação Empresa-Escola de Engenharia (FEENG) da UFRGS, foi elaborado um projeto direcionado ao desenvolvimento da comunidade judaica gaúcha. 0 objetivo desse projeto, intitulado "Comunidade Judaica - Século XXl”, consistiu na elaboração do escopo preliminar de seis projetos estratégicos para as próximas décadas.
A Firgs é uma entidade que representa a comunidade judaica gaúcha e visa a integração dos seus membros, estimulando o espírito de união. A comunidade judaica gaúcha conta com cerca de 15 mil indivíduos e 42 entidades vinculam-se à Firgs, atuantes em segmentos como: educação, assistência social, saúde, cultura e religião (FEDERAÇÃO..., 2007).

0 trabalho aplicado envolveu o desenvolvimento de projetos em diferentes segmentos, tais como: assistência social, educação e emprego, cultura, religião, patrimônio e gestão. Assim, no que concerne à representatividade da amostra, sendo uma pesquisa qualitativa, a mesma não apresenta representatividade estatística, contudo possui diversidade suficiente (conforme desejado nos estudos qualitativos) para propiciar um teste adequado da abordagem proposta.

\subsection{Planejamento}

Considerando-se o nível de maturidade da organização sob estudo, a iniciação de projetos foi planejada a partir de atividades que pudessem ser intuitivamente compreendidas pelos envolvidos. A primeira etapa iniciou com uma reunião conduzida pela diretoria da Firgs, com a participação dos conselheiros da organização e dos pesquisadores da Feeng. Os pesquisadores integraram a equipe técnica do projeto e coube à diretoria e aos conselheiros da Firgs a tarefa de compor o conselho gestor. Normalmente, a iniciação é realizada por equipe da alta administração e pressupõe que sponsors se responsabilizem politicamente perante a alta administração, desenvolvendo e defendendo as oportunidades identificadas.

Após a constituição das equipes, os profissionais iniciaram o detalhamento das etapas. Foram identificadas as informações necessárias para a realização do projeto e os locais onde essas informações poderiam ser obtidas. Após, foram verificadas e selecionadas as alternativas de atividade mais adequadas às características da Firgs para 0 levantamento dessas informações.

0 Quadro 3 apresenta uma síntese desse processo de identificação e seleção, apontando as alternativas e seus aspectos positivos e negativos e assinalando as atividades que foram efetivamente adotadas. Após, foram definidos os prazos para realização das atividades detalhadas na etapa anterior.

\subsection{Coleta de informações}

$\mathrm{Na}$ inexistência de documentos adequados à coleta de informações, esses tiveram que ser propostos. Os instrumentos selecionados para a coleta de informações permitiram o envolvimento de grande número de 
Silveira, P. et al.

Abordagem para identificação... desenvolvimento e estudo de caso. Produção, v. 22, n. 3, p. 448-461, maio/ago. 2012

Quadro 2. Resumo da abordagem proposta.

\begin{tabular}{|c|c|c|c|c|c|}
\hline Macroetapas & Etapas & $\begin{array}{l}\text { Condução de } \\
\text { atividades }\end{array}$ & $\begin{array}{c}\text { Função do conselho } \\
\text { gestor }\end{array}$ & $\begin{array}{l}\text { Função da equipe } \\
\text { técnica }\end{array}$ & Resultado da etapa \\
\hline \multirow{3}{*}{ Planejamento } & $\begin{array}{l}\text { 1. Constituição das } \\
\text { equipes de trabalho }\end{array}$ & $\begin{array}{l}\text { - Reunião de diretoria } \\
\text { e conselho para } \\
\text { revisão da identidade } \\
\text { organizacional; } \\
\text { - Indicação de } \\
\text { profissionais } \\
\text { habilitados para } \\
\text { integrar equipes; } \\
\text { - Alocação dos } \\
\text { profissionais em } \\
\text { funções específicas no } \\
\text { conselho gestor e na } \\
\text { equipe técnica. }\end{array}$ & $\begin{array}{l}\text { - Definir constituição } \\
\text { das equipes. }\end{array}$ & - & $\begin{array}{l}\text { Documento formalizando } \\
\text { a constituição das equipes } \\
\text { de trabalho contendo: } \\
\text { dados dos integrantes } \\
\text { (informações profissionais } \\
\text { e contatos), funções, } \\
\text { prazos previstos para } \\
\text { realizações, resultados } \\
\text { esperados e outras } \\
\text { informações relevantes. }\end{array}$ \\
\hline & $\begin{array}{l}\text { 2. Detalhamento das } \\
\text { etapas }\end{array}$ & $\begin{array}{l}\text { - Identificação de } \\
\text { atividades alternativas } \\
\text { para condução das } \\
\text { etapas da abordagem; } \\
\text { - Seleção das } \\
\text { atividades adequadas } \\
\text { às características da } \\
\text { organização; } \\
\text { - Descrição dos } \\
\text { procedimentos } \\
\text { para realização das } \\
\text { atividades adotadas. }\end{array}$ & $\begin{array}{l}\text { - Selecionar } \\
\text { atividades adequadas } \\
\text { às características da } \\
\text { organização; } \\
\text { - Aprovar } \\
\text { procedimentos } \\
\text { para realização das } \\
\text { atividades adotadas. }\end{array}$ & \begin{tabular}{|l|} 
- Identificar atividades \\
alternativas; \\
- Amparar tecnicamente \\
o processo de seleção \\
das atividades; \\
- Selecionar atividades \\
adequadas às \\
características da \\
organização; \\
- Descrever os \\
procedimentos \\
para realização das \\
atividades adotadas.
\end{tabular} & $\begin{array}{l}\text { Relatório final das } \\
\text { atividades adotadas, } \\
\text { preferencialmente } \\
\text { organizado em planilha, } \\
\text { com a descrição dos } \\
\text { procedimentos para } \\
\text { realização das atividades } \\
\text { componentes de cada } \\
\text { etapa da abordagem. }\end{array}$ \\
\hline & 3. Definição dos prazos & $\begin{array}{l}\text { (i) Utilização do } \\
\text { diagrama de setas; } \\
\text { (ii) Utilização } \\
\text { de softwares de } \\
\text { planejamento e } \\
\text { gestão, como o } \\
\text { MS-Project }{ }^{\odot} \text {. }\end{array}$ & $\begin{array}{l}\text { - Participar do } \\
\text { planejamento dos } \\
\text { cronogramas; } \\
\text { - Aprovar os } \\
\text { cronogramas. }\end{array}$ & $\begin{array}{l}\text { - Conduzir o } \\
\text { planejamento dos } \\
\text { cronogramas. }\end{array}$ & $\begin{array}{l}\text { Cronograma organizado, } \\
\text { preferencialmente, como } \\
\text { gráfico de Gantt, contendo } \\
\text { a duração das tarefas, as } \\
\text { relações de precedência, } \\
\text { os prazos e as capacidades } \\
\text { disponíveis. }\end{array}$ \\
\hline \multirow{2}{*}{$\begin{array}{c}\text { Coleta de } \\
\text { informações }\end{array}$} & $\begin{array}{l}\text { 4. Desenvolvimento } \\
\text { e aplicação dos } \\
\text { instrumentos de coleta } \\
\text { de informação }\end{array}$ & $\begin{array}{l}\text { (i) Análise de } \\
\text { documentos; } \\
\text { (ii) Caixas de } \\
\text { sugestões; } \\
\text { (iii) Brainstorming; } \\
\text { (iv) Questionários } \\
\text { aplicados; } \\
\text { (v) Entrevistas em } \\
\text { profundidade; } \\
\text { (vi) Grupos focados. }\end{array}$ & $\begin{array}{l}\text { - Avaliar e aprovar } \\
\text { os instrumentos de } \\
\text { coleta de informação } \\
\text { desenvolvidos; } \\
\text { - Avaliar e aprovar } \\
\text { os resultados: } \\
\text { relatório resumo } \\
\text { de informações } \\
\text { coletadas. }\end{array}$ & $\begin{array}{l}\text { - Desenvolver os } \\
\text { instrumentos de coleta } \\
\text { de informação; } \\
\text { - Aplicar os } \\
\text { instrumentos de coleta } \\
\text { de informação; } \\
\text { - Avaliar os resultados: } \\
\text { relatório resumo de } \\
\text { informações coletadas. }\end{array}$ & $\begin{array}{l}\text { Relatório resumo de } \\
\text { informações coletadas } \\
\text { contemplando informações } \\
\text { acerca de todos os } \\
\text { segmentos visados } \\
\text { (públicos-alvo), conforme } \\
\text { previsto na primeira } \\
\text { macroetapa. }\end{array}$ \\
\hline & $\begin{array}{l}\text { 5. Tabulação das } \\
\text { informações }\end{array}$ & $\begin{array}{l}\text { - Classificação das } \\
\text { informações em } \\
\text { blocos comuns de } \\
\text { oportunidades; } \\
\text { - Padronização dos } \\
\text { termos utilizados, } \\
\text { eliminação de } \\
\text { redundâncias e } \\
\text { desdobramento de } \\
\text { informações. } \\
\end{array}$ & - & $\begin{array}{l}\text { - Tabular informações; } \\
\text { - Preparar estatísticas e } \\
\text { quadros-resumo. }\end{array}$ & $\begin{array}{l}\text { Listas de informações } \\
\text { comuns: blocos de } \\
\text { oportunidades. }\end{array}$ \\
\hline \multirow{2}{*}{$\begin{array}{l}\text { Identificação de } \\
\text { oportunidades }\end{array}$} & $\begin{array}{l}\text { 6. Análise dos blocos de } \\
\text { oportunidades }\end{array}$ & $\begin{array}{l}\text { (i) Análise de } \\
\text { conteúdo; } \\
\text { (ii) Diagrama de } \\
\text { afinidade; } \\
\text { (iii) Seminário. }\end{array}$ & - & $\begin{array}{l}\text { - Analisar blocos de } \\
\text { oportunidades. }\end{array}$ & $\begin{array}{l}\text { Pré-projetos (project } \\
\text { charters), identificando } \\
\text { áreas de atuações e } \\
\text { especificando ações } \\
\text { práticas e viáveis para } \\
\text { o desenvolvimento dos } \\
\text { objetivos específicos } \\
\text { dessas áreas através de } \\
\text { projetos de mudanças e } \\
\text { desenvolvimento. }\end{array}$ \\
\hline & $\begin{array}{l}\text { 7. Priorização dos } \\
\text { pré-projetos (project } \\
\text { charters) }\end{array}$ & $\begin{array}{l}\text { (i) Matriz de } \\
\text { priorização; } \\
\text { (ii) Método AHP; } \\
\text { (iii) Matriz de } \\
\text { classificação de } \\
\text { portfólios; } \\
\text { (iv) Plebiscito. }\end{array}$ & $\begin{array}{l}\text { - Verificar a } \\
\text { consistência dos } \\
\text { resultados da } \\
\text { priorização; } \\
\text { - Dependendo do } \\
\text { método empregado } \\
\text { de priorização, } \\
\text { participar ativamente } \\
\text { da etapa. }\end{array}$ & $\begin{array}{l}\text { - Conduzir métodos de } \\
\text { priorização. }\end{array}$ & $\begin{array}{l}\text { Lista com pré-projetos } \\
\text { ordenados segundo } \\
\text { critérios pré-estabelecidos } \\
\text { de priorização, conforme } \\
\text { características da } \\
\text { organização. }\end{array}$ \\
\hline
\end{tabular}


Quadro 2. Continuação...

\begin{tabular}{|c|c|c|c|c|c|}
\hline Macroetapas & Etapas & $\begin{array}{l}\text { Condução de } \\
\text { atividades }\end{array}$ & $\begin{array}{c}\text { Função do conselho } \\
\text { gestor }\end{array}$ & $\begin{array}{l}\text { Função da equipe } \\
\text { técnica }\end{array}$ & Resultado da etapa \\
\hline \multirow{3}{*}{$\begin{array}{l}\text { Concepção de } \\
\text { projetos }\end{array}$} & $\begin{array}{l}\text { 8. Redação da declaração } \\
\text { do escopo preliminar dos } \\
\text { projetos }\end{array}$ & $\begin{array}{l}\text { - Desenvolver } \\
\text { a estrutura dos } \\
\text { formulários de redação } \\
\text { de projetos; } \\
\text { - Preencher os } \\
\text { formulários de redação } \\
\text { de projetos. }\end{array}$ & $\begin{array}{l}\text { - Selecionar } \\
\text { participantes para a } \\
\text { redação dos projetos. }\end{array}$ & $\begin{array}{l}\text { - Desenvolver estrutura } \\
\text { dos formulários de } \\
\text { redação do escopo } \\
\text { preliminar dos projetos; } \\
\text { - Realizar } \\
\text { pré-preenchimento dos } \\
\text { formulários; } \\
\text { - Conduzir } \\
\text { preenchimento dos } \\
\text { formulários. }\end{array}$ & $\begin{array}{l}\text { Formulários de declaração } \\
\text { do escopo preliminar } \\
\text { dos projetos, contendo } \\
\text { exemplos genéricos; } \\
\text { Projetos finais. }\end{array}$ \\
\hline & $\begin{array}{l}\text { 9. Aprovação da } \\
\text { declaração do escopo } \\
\text { preliminar dos projetos }\end{array}$ & - & $\begin{array}{l}\text { - Aprovar e fazer } \\
\text { eventuais ajustes no } \\
\text { escopo preliminar. }\end{array}$ & $\begin{array}{l}\text { - Remeter as versões } \\
\text { finais das declarações } \\
\text { do escopo preliminar } \\
\text { dos projetos para } \\
\text { aprovação do conselho } \\
\text { gestor. }\end{array}$ & $\begin{array}{l}\text { Versões finais das } \\
\text { declarações de escopo } \\
\text { preliminar aprovadas. }\end{array}$ \\
\hline & $\begin{array}{l}\text { 10. Divulgação da } \\
\text { declaração do escopo } \\
\text { preliminar dos projetos }\end{array}$ & $\begin{array}{l}\text { (i) Evento: almoço } \\
\text { ou jantar de } \\
\text { encerramento, } \\
\text { assembléia geral ou } \\
\text { workshop; } \\
\text { (ii) Publicação: em } \\
\text { jornais, em circulares } \\
\text { ou na web. }\end{array}$ & $\begin{array}{l}\text { - Prestigiar o evento; } \\
\text { - Auxiliar na } \\
\text { organização do } \\
\text { evento; } \\
\text { - Reforçar conotação } \\
\text { política de } \\
\text { continuidade dos } \\
\text { esforços; } \\
\text { - Definir o que pode } \\
\text { e o que não deve ser } \\
\text { divulgado; } \\
\text { - Definir veículos } \\
\text { de comunicação } \\
\text { utilizados. }\end{array}$ & $\begin{array}{l}\text { - Organizar evento de } \\
\text { divulgação dos projetos } \\
\text { finais; } \\
\text { - Organizar } \\
\text { apresentação dos } \\
\text { projetos desenvolvidos; } \\
\text { - Apresentar projetos } \\
\text { para os membros da } \\
\text { organização; } \\
\text { - Promover } \\
\text { engajamento } \\
\text { dos membros da } \\
\text { organização para } \\
\text { participação nas etapas } \\
\text { futuras - executivas } \\
\text { (“vender os projetos”). }\end{array}$ & $\begin{array}{l}\text { Versão final da declaração } \\
\text { do escopo preliminar dos } \\
\text { projetos divulgados. }\end{array}$ \\
\hline
\end{tabular}

indivíduos e de diferentes áreas de atuação da comunidade judaica, atendendo o pressuposto de participação necessário aos processos de organizações sociais. De acordo com o processo de seleção apresentado no Quadro 3, os instrumentos adotados foram: (i) análise de documentos, (ii) questionários aplicados, (iii) entrevistas em profundidade e (iv) grupos focados.

(i) Análise de documentos históricos

A análise contemplou a reunião dos materiais de projetos de desenvolvimento empreendidos por entidades judaicas e por gestões anteriores da Firgs, desde sua criação, em abril de 1961. Foram listados os fatos mais destacados em uma linha de tempo. Assim foi possível observar a evolução da comunidade judaica gaúcha no contexto da Firgs e apontar caminhos de desenvolvimento.

(ii) Questionários aplicados junto a famílias e indivíduos

Embora não sejam descritos com a mesma frequência que na área de projetos de desenvolvimento de produto, as entrevistas qualitativas e quantitativas são importantes instrumentos para a iniciação de projetos.

Foram desenvolvidos questionários para analisar a situação atual e as expectativas dos integrantes da comunidade, focando famílias e indivíduos. Por tratar-se de uma organização comunitária com características particulares, o instrumento possibilitou que informações específicas, na conjuntura do judaísmo, fossem obtidas, compreendendo uma amostra significativa. A consulta abrangeu 580 famílias e 750 indivíduos. As Figuras 1 e 2 apresentam exemplos dos resultados levantados.

(iii) Entrevistas em profundidade junto a entidades

Foi desenvolvido um questionário para levantar a situação e as expectativas das entidades judaicas no Rio Grande do Sul. Esses questionários foram aplicados na forma de entrevistas, a partir de uma amostra representativa de entidades. Para a realização das entrevistas, foram selecionadas 28 das 42 entidades judaicas gaúchas.

(iv) Grupos focados com especialistas

Foram conduzidos quatro grupos focados, contando com seis especialistas convidados para discutir os temas: (i) religião, (ii) educação e cultura, (iii) patrimônio e (iv) assistência social.

De acordo com a abordagem, após a coleta de todas as informações, as mesmas foram tabuladas, iniciando a classificação e alocação das opiniões em blocos comuns de oportunidades. Constituíram-se sete blocos de oportunidades: bloco 1 - assistência social, 
Silveira, P. et al.

Abordagem para identificação... desenvolvimento e estudo de caso. Produção, v. 22, n. 3, p. 448-461, maio/ago. 2012

Quadro 3. Processo de seleção de atividades para condução das etapas da abordagem proposta no projeto Comunidade Judaica - Século XXI.

\begin{tabular}{|c|c|c|c|c|c|}
\hline Macroetapas & Etapas & $\begin{array}{l}\text { Atividades } \\
\text { alternativas }\end{array}$ & Aspectos positivos & Aspectos negativos & Aplicação \\
\hline \multirow{7}{*}{$\begin{array}{l}\text { 2a Macroetapa: } \\
\text { coleta de } \\
\text { informações }\end{array}$} & \multirow{6}{*}{$\begin{array}{l}\text { 4. Desenvolvimento e aplicação } \\
\text { dos instrumentos de coletas de } \\
\text { informações }\end{array}$} & $\begin{array}{l}\text { (i) Análise de } \\
\text { documentos }\end{array}$ & $\begin{array}{l}\text { A Firgs, que já realizou } \\
\text { outros projetos de } \\
\text { desenvolvimento, } \\
\text { contava com acervo de } \\
\text { materiais: documentos, } \\
\text { registros e históricos. }\end{array}$ & $\begin{array}{l}0 \text { material } \\
\text { encontrava-se } \\
\text { desorganizado e } \\
\text { descentralizado. Além } \\
\text { disso, parte do acervo } \\
\text { não obteve autorização } \\
\text { para publicação. }\end{array}$ & Sim \\
\hline & & $\begin{array}{l}\text { (ii) Caixas de } \\
\text { sugestões }\end{array}$ & $\begin{array}{l}\text { Seria facilmente } \\
\text { implementável tanto na } \\
\text { federação quanto nas } \\
\text { sedes das entidades. }\end{array}$ & $\begin{array}{l}0 \text { período de } \\
\text { mobilização para } \\
\text { utilização deste recurso } \\
\text { poderia ultrapassar os } \\
\text { prazos planejados. }\end{array}$ & Não \\
\hline & & (iii) Brainstorming & $\begin{array}{l}\text { Seria facilmente } \\
\text { aplicável e não } \\
\text { requereria recursos } \\
\text { vultosos. }\end{array}$ & $\begin{array}{l}\text { Focaria a identificação } \\
\text { de causas específicas } \\
\text { para problemas } \\
\text { determinados e não } \\
\text { a identificação de } \\
\text { problemas. } \\
\end{array}$ & Não \\
\hline & & $\begin{array}{l}\text { (iv) Questionários } \\
\text { aplicados }\end{array}$ & $\begin{array}{l}\text { Facilitaria a obtenção } \\
\text { de informações } \\
\text { específicas no contexto } \\
\text { do judaísmo. }\end{array}$ & $\begin{array}{l}\text { A Firgs, que representa } \\
\text { entidades com sedes } \\
\text { descentralizadas, teria } \\
\text { dificuldades para } \\
\text { coletar os questionários } \\
\text { respondidos. }\end{array}$ & Sim \\
\hline & & $\begin{array}{l}\text { (v) Entrevistas em } \\
\text { profundidade }\end{array}$ & $\begin{array}{l}\text { Facilitaria a obtenção de } \\
\text { informações específicas } \\
\text { das entidades da } \\
\text { comunidade judaica. }\end{array}$ & $\begin{array}{l}0 \text { período dispensado } \\
\text { para agendamentos, } \\
\text { visitas e formatação das } \\
\text { entrevistas remeteria } \\
\text { à seleção de entidades } \\
\text { determinadas. }\end{array}$ & Sim \\
\hline & & (vi) Grupos focados & $\begin{array}{l}\text { Permitiria levantar } \\
\text { informações específicas } \\
\text { dos segmentos atuantes } \\
\text { da comunidade judaica, } \\
\text { através de discussões } \\
\text { entre diferentes pontos } \\
\text { de vistas. } \\
\end{array}$ & $\begin{array}{l}\text { Apresentaria } \\
\text { dificuldades para } \\
\text { compatibilizar a agenda } \\
\text { de vários colaboradores. }\end{array}$ & Sim \\
\hline & 5. Tabulação das informações & Planilha eletrônica & $\begin{array}{l}\text { Facilidade de gerar } \\
\text { tabulações e gráficos. }\end{array}$ & - & Sim \\
\hline \multirow{7}{*}{$\begin{array}{l}\text { 3a Macroetapa: } \\
\text { identificação de } \\
\text { oportunidades }\end{array}$} & \multirow{3}{*}{$\begin{array}{l}\text { 6. Análise dos blocos de } \\
\text { oportunidades }\end{array}$} & $\begin{array}{l}\text { (i) Análise de } \\
\text { conteúdo }\end{array}$ & $\begin{array}{l}\text { Permitiria a organização } \\
\text { das ideias em uma lista } \\
\text { organizada. }\end{array}$ & $\begin{array}{l}\text { Não possibilitaria o } \\
\text { envolvimento de muitos } \\
\text { integrantes. }\end{array}$ & Não \\
\hline & & $\begin{array}{l}\text { (ii) Diagrama de } \\
\text { afinidade }\end{array}$ & $\begin{array}{l}\text { Possibilitaria a adição } \\
\text { de novas informações e } \\
\text { grupos de discussão. }\end{array}$ & - & Não \\
\hline & & (iii) Seminário & $\begin{array}{l}\text { Possibilitaria a adição } \\
\text { de informações e } \\
\text { grupos de discussão, } \\
\text { anteciparia a elaboração } \\
\text { das diretrizes de } \\
\text { projetos e promoveria } \\
\text { engajamento. }\end{array}$ & $\begin{array}{l}\text { Dispensaria } \\
\text { infraestrutura } \\
\text { adequada nas etapas } \\
\text { de planejamento e } \\
\text { condução do evento. }\end{array}$ & Sim \\
\hline & \multirow{4}{*}{$\begin{array}{l}\text { 7. Priorização dos pré-projetos } \\
\text { (project charters) }\end{array}$} & $\begin{array}{l}\text { (i) Matriz de } \\
\text { priorização }\end{array}$ & $\begin{array}{l}\text { A aplicação seria } \\
\text { simples e objetiva. }\end{array}$ & \begin{tabular}{|l} 
Requereria a \\
combinação de uma \\
análise qualitativa do \\
resultado final.
\end{tabular} & Sim \\
\hline & & (ii) Método AHP & $\begin{array}{l}\text { A aplicação seria } \\
\text { facilitada por apresentar } \\
\text { etapas bem definidas. }\end{array}$ & $\begin{array}{l}\text { Requereria muito tempo } \\
\text { para as tomadas de } \\
\text { decisão. }\end{array}$ & Não \\
\hline & & $\begin{array}{l}\text { (iii) Matriz de } \\
\text { classificação }\end{array}$ & $\begin{array}{l}\text { A aplicação seria } \\
\text { simples e objetiva. }\end{array}$ & $\begin{array}{l}\text { Abordaria elementos } \\
\text { desnecessários } \\
\text { no contexto de } \\
\text { organizações sociais. }\end{array}$ & Não \\
\hline & & (iv) Plebiscito & $\begin{array}{l}\text { A votação seria objetiva } \\
\text { e não presencial. }\end{array}$ & $\begin{array}{l}\text { Não possibilitaria } \\
\text { adicionar novas } \\
\text { informações. }\end{array}$ & Não \\
\hline
\end{tabular}


Quadro 3. Continuação...

\begin{tabular}{|c|c|c|c|c|c|c|}
\hline Macroetapas & \multicolumn{2}{|l|}{ Etapas } & $\begin{array}{l}\text { Atividades } \\
\text { alternativas }\end{array}$ & Aspectos positivos & Aspectos negativos & Aplicação \\
\hline \multirow{6}{*}{$\begin{array}{l}\text { 4a Macroetapa: } \\
\text { concepção de } \\
\text { projetos }\end{array}$} & \multirow{2}{*}{$\begin{array}{l}\text { 8. Redação da } \\
\text { declaração do escopo } \\
\text { preliminar dos } \\
\text { projetos }\end{array}$} & $\begin{array}{l}8.1 \\
\text { Desenv. de } \\
\text { formul. } \\
\end{array}$ & $\begin{array}{l}\text { Poderiam ser } \\
\text { desenvolvidos. }\end{array}$ & $\begin{array}{l}\text { Facilidade de reunir } \\
\text { informações relevantes, } \\
\text { seguindo o roteiro. }\end{array}$ & $\begin{array}{l}\text { Apresentaria um único } \\
\text { modelo para todos os } \\
\text { tipos de projeto. }\end{array}$ & Sim \\
\hline & & $\begin{array}{l}8.2 \\
\text { Preenc. de } \\
\text { formul. } \\
\end{array}$ & $\begin{array}{l}\text { Sem o uso de } \\
\text { formulário. }\end{array}$ & \begin{tabular}{|l} 
Facilidade de \\
preenchimento de \\
tópicos pré-elaborados.
\end{tabular} & \begin{tabular}{|l} 
Alguns tópicos \\
poderiam não ser \\
pertinentes.
\end{tabular} & Sim \\
\hline & \multirow{2}{*}{\multicolumn{2}{|c|}{$\begin{array}{l}\text { 9. Aprovação da declaração do } \\
\text { escopo preliminar dos projetos }\end{array}$}} & $\begin{array}{l}\text { (i) Reunião do } \\
\text { conselho gestor }\end{array}$ & Consenso do conselho & $\begin{array}{l}\text { A aprovação final } \\
\text { não envolveria a } \\
\text { comunidade. }\end{array}$ & Sim \\
\hline & & & (ii) Plebiscito & $\begin{array}{l}\text { Envolvimento da } \\
\text { comunidade. }\end{array}$ & $\begin{array}{l}\text { Demandaria tempo: } \\
\text { a decisão estaria nas } \\
\text { mãos de pessoas } \\
\text { inexperientes. } \\
\end{array}$ & Não \\
\hline & \multirow{2}{*}{\multicolumn{2}{|c|}{$\begin{array}{l}\text { 10. Divulgação da declaração do } \\
\text { escopo preliminar dos projetos }\end{array}$}} & $\begin{array}{l}\text { (i) Realização de } \\
\text { evento }\end{array}$ & \begin{tabular}{|l|} 
Promoveria \\
engajamento e \\
participação da \\
comunidade. \\
\end{tabular} & \begin{tabular}{|l|} 
Dispensaria \\
infraestrutura adequada \\
para condução do \\
evento. \\
\end{tabular} & Sim \\
\hline & & & (ii) Publicações & $\begin{array}{l}\text { Atingiria maior número } \\
\text { de integrantes. }\end{array}$ & $\begin{array}{l}\text { Requereria maiores } \\
\text { recursos. }\end{array}$ & Sim \\
\hline
\end{tabular}

Você se sente parte da comunidade judaica?

\begin{tabular}{|r|c|c|c|c|c|c|c|c|c|c|}
\hline Nada & $5 \%$ & 33 \\
\hline Um pouco & $32 \%$ & 233 \\
\hline Muito & $39 \%$ & 288 \\
\hline Extremamente & $24 \%$ & 179 \\
\hline Total & $100 \%$ & 733 & & & \\
\hline
\end{tabular}

Figura 1. Resultados sobre o engajamento dos integrantes com a comunidade judaica.

Assuntos que preocupam

\begin{tabular}{|r|c|c|}
\hline Violência & $82 \%$ & 610 \\
\hline Falta de segurança & $76 \%$ & 565 \\
\hline Anti-semitismo & $61 \%$ & 455 \\
\hline Problemas econômicos & $39 \%$ & 285 \\
\hline Desemprego & $38 \%$ & 282 \\
\hline Falta de saúde & $33 \%$ & 245 \\
\hline Problemas educacionais & $29 \%$ & 216 \\
\hline Formação profissional & $23 \%$ & 172 \\
\hline Solidão & $13 \%$ & 98 \\
\hline Outros & $6 \%$ & 41 \\
\hline
\end{tabular}

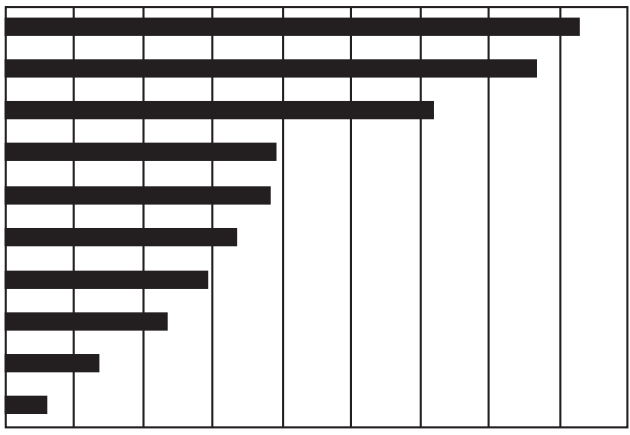

Figura 2. Resultados sobre os assuntos que preocupam os integrantes da comunidade judaica.

bloco 2 - educação e emprego, bloco 3 - cultura, bloco 4 - religião e valores, bloco 5 - patrimônio e recursos, bloco 6 - informação e bloco 7 - liderança e mobilização.

\subsection{Identificação de oportunidades}

A terceira macroetapa da abordagem envolveu a realização de um seminário. Nessa etapa, os blocos de oportunidades passaram por análise técnica, constituindo os pré-projetos (project charters). 0 seminário marcou a participação da comunidade no projeto, promovendo engajamento e integração dos membros. Cerca de 150 pessoas participaram das discussões temáticas definidas pelos sete blocos de oportunidades.

Além das ideias gerais que foram discutidas pelos grupos do seminário, foram identificados 20 pré-projetos de interesse para a comunidade judaica. Após, a etapa de priorização consistiu em uma avaliação técnica dos pré-projetos identificados. Foram adotados oito critérios de priorização, alocados em dois blocos: benefícios que os projetos poderiam gerar e esforços associados. 
0 bloco dos benefícios considerou os critérios: (i) benefícios para a comunidade judaica do RS, (ii) para a comunidade em geral do RS, (iii) potencial para propiciar engajamento e (iv) contribuição para a imagem da comunidade. 0 bloco dos esforços associados considerou: (v) esforço técnico necessário, (vi) esforço político necessário, (vii) força de trabalho necessária (hora-homem) e (viii) esforço financeiro necessário.

A priorização promoveu o ordenamento dos pré-projetos. A priorização técnica indicou cinco projetos prioritários. Em seguida, um estudo qualitativo realizado pelo conselho gestor validou os projetos priorizados e incorporou um sexto projeto, necessário para assegurar a consistência dos demais projetos. Os seis pré-projetos priorizados foram: (i) Excelência na educação, (ii) Divulgar, (iii) Cultura judaica, (iv) Juventude participativa, (v) Assistência multidisciplinar e (vi) Planejamento comunitário (incluído pelo conselho gestor).

A teoria de gestão de portfólio dentro da literatura de gestão de projetos confirma as atividades de identificação, análise, seleção, priorização de propostas semelhantes às que foram desenvolvidas nesta organização social. Na verdade, a gestão de portfólio se confunde com a iniciação de projetos na literatura, podendo ser compreendida como um instrumento dentro dos processos de iniciação de projetos.

\subsection{Concepção de projetos}

A elaboração das declarações de escopo preliminar dos projetos consistiu na sistematização e detalhamento das informações dos seis pré-projetos (project charters) priorizados em ações concretas, segundo uma estrutura pré-definida, que contemplou as informações essenciais para a formulação de propostas executivas.

Terminadas as etapas técnicas, iniciaram-se os esforços políticos de divulgação e aceitação dos projetos gerados. Na medida em que os projetos possuíam valor intrínseco para a comunidade, a aceitação foi facilitada.

Não fez parte deste trabalho desenvolver o "controle de alto nível do escopo do projeto" junto à declaração do escopo preliminar, conforme preconizam o PMBoK (PROJECT..., 2008) e Xavier (2005). Esse controle determina como serão solicitadas e controladas as mudanças de escopo ao longo do projeto, quem deverá autorizá-las e quais estudos deverão ser realizados para analisar o impacto das modificações do escopo sobre a qualidade, tempo e custos do projeto. Este controle é parte da metodologia de gestão de projetos da organização, quando e se houver uma evolução nesse sentido, por isso não foi abordado neste trabalho.

\section{Conclusões}

Frente às dificuldades encontradas por organizações sociais para desenvolver projetos, este artigo propõe a aplicação de uma abordagem para identificação de oportunidades e elaboração do escopo preliminar de projetos, desenvolvida a partir da lógica de identificação de expectativas e necessidades, em sinergia com a cultura da organização.

Os projetos abordados nesse caso são aqueles onde o grau de inovação é baixo ou moderado e ao longo dos quais não há grandes variações de escopo, portanto podem ser controlados por documentações como as apresentadas neste estudo. Em virtude do nível inicial de maturidade da organização social sob estudo em relação à gestão de projetos e à gestão de negócios, tratou-se o tema a partir do enfoque da iniciação de projetos, sem aprofundamento nas técnicas mais sofisticadas de gestão de portfólio.

Dessa forma, a proposta está estruturada em dez etapas, que contemplam: (i) constituição das equipes de trabalhos, (ii) detalhamento das etapas, (iii) definição dos prazos, (iv) desenvolvimento e aplicação dos instrumentos de coleta de informações, (v) tabulação das informações, (vi) análise dos blocos de oportunidades, (vii) priorização dos pré-projetos (project charters), (viii) redação da declaração do escopo preliminar dos projetos, (ix) aprovação da declaração do escopo preliminar dos projetos e (x) divulgação da declaração do escopo preliminar dos projetos.

A abordagem proposta foi aplicada em uma organização social comunitária judaica centralizadora, representativa de 42 entidades que atuam em diferentes segmentos. Essa variedade proporcionou o enriquecimento da pesquisa, uma vez que em uma única aplicação puderam-se perceber variantes de diferentes áreas. A condução do estudo aplicado seguiu as etapas propostas. Foram geradas seis oportunidades de projetos, abrangendo diferentes áreas, contemplando transformação e promovendo o empenho dos integrantes da comunidade nas etapas futuras de gestão dos projetos gerados - etapas executivas.

A aplicação da abordagem pode ser considerada como de sucesso, uma vez que promoveu notável engajamento dos associados da organização em todas as etapas. As alterações resultantes das dificuldades encontradas ao longo da aplicação prática foram implementadas e fazem parte da estrutura final da abordagem, uma vez que os procedimentos desta pesquisa caracterizaram-se como de pesquisa-ação, em que as atividades e as propostas interagem ao longo da evolução da pesquisa.

A realização deste trabalho contribui para o avanço da área de gestão de projeto por apresentar 
uma aplicação pormenorizada da fase de iniciação, incluindo ferramentas de investigação e de seleção de propostas de projetos identificadas no mercado. Conforme mencionado na literatura (XAVIER, 2005; PROJECT..., 2008; VERZUH, 2000), os processos de iniciação são frequentemente realizados fora do escopo de controle do projeto. Em outras palavras, a iniciação normalmente não é desenvolvida pela equipe de projeto. Por essa razão, é fundamental que seja conduzida com o necessário cuidado e nível de detalhamento, para gerar diretrizes efetivamente claras, que serão seguidas, posteriormente, pela equipe de projeto. Os processos de iniciação podem ser realizados de distintas formas e a abordagem apresentada neste trabalho contribui trazendo formalidade e estrutura para os processos de iniciação.

Para trabalhos futuros, sugere-se a elaboração de um método adaptado às organizações sociais, contemplando as demais fases do ciclo de vida de gestão dos projetos, o que exigiria etapas específicas prevendo medidas de contingência frente às típicas dificuldades enfrentadas por essas organizações.

\section{Referências}

AAKER, D. A.; KUMAR, V.; DAY, G. S. Pesquisa de Marketing. São Paulo: Atlas, 2001

AMERICAN MARKETING ASSOCIATION - AMA. Disponível em: <www.marketingpower.com>. Acesso em: 04 abr. 2007.

ARMANI, D. Como Elaborar Projetos? Guia Prático para Elaboração e Gestão de Projetos Sociais. Porto Alegre: Tomo Editorial, 2001.

ASHOKA, E. S.; McKINSEY C. Empreendimentos Sociais Sustentáveis: Como Elaborar Planos de Negócios para Organizações Sociais. São Paulo: Editora Peirópolis, 2001.

BARTOLl, A.; HERMEL, P. Managing change and innovation in IT implementation process. Journal of Manufacturing Technology Management, v. 15, n. 5, p. 416-424, 2004. http://dx.doi.org/10.1108/17410380410540417

BOSSIDY, L. A Receita da Execução. Revista HSM Management, n. 51, 2005.

CASAROTTO FILHO, N. Anteprojeto Industrial: das Estratégias Empresariais à Engenharia. 1995. Tese (Doutorado em Engenharia)-Universidade Federal de Santa Catarina, Florianópolis, 1995.

CHARVAT, J. Project Management Methodologies: Selecting, Implementing, and Supporting Methodologies and Processes for Projects. New York: John Wiley \& Sons, 2003.

CHRISTENSEN, C. M.; OVERDORF, M. Enfrentando o Desafio da Mudança Revolucionária. Harvard Business Review, 2000.

COVEY, S. Atrair e Reter Talentos, o Novo Desafio. Revista HSM Management, n. 32, 2002

CRAWFORD, M.; BENEDETTO, C. A. New Products Management. 6. ed. Boston: McGraw Hill, 2000.
CRUZ, C.; ESTRAVIZ, M. Captação de Diferentes Recursos para Organizações da Sociedade Civil. São Paulo: Global Editora, 2000.

DEES, J. G.; EMERSON, J.; ECONOMY, P. Enterprising nonprofits: a toolkit for social entrepreneurs. New York: John Willey and Sons, 2001.

DUCK, J. D. Gerenciando a Mudança: a Arte do Equilíbrio. Harvard Business Review, 1993.

FAlCON, A. P. A Promessa do Terceiro Setor. 1999. Dissertação (Mestrado em Administração)-Faculdade de Economia e Administração, Universidade de São Paulo, São Paulo, 1999.

FEDERAÇÃO ISRAELITA DO RIO GRANDE DO SUL - FIRGS. Projeto da Comunidade Judaica do Rio Grande do Sul para o Século XXI. Porto Alegre: FIRGS, 2007. Disponível em: <www.seculo21.producao.ufrgs.br> Acesso em: 19 dez. 2006.

INSTITUTO DE DESENVOLVIMENTO GERENCIAL - INDG. Disponivel em: <www.indg.com.br/> Acesso em: 26 mar. 2007.

JESTON, J.; NELIS, J. Business Process Management Practical Guidelines to Successful Implementations. 2. ed. Elsevier, 2008.

JONES, J.; CALDERONE, M.; AGUIRRE, D. 10 Passos para Mudar as Pessoas. Strategy \& Business, 2004.

KEELLING, R. Gestão de Projetos: uma Abordagem Global. São Paulo: Saraiva, 2002.

KERZNER, H. Gestão de Projetos: as Melhores Práticas. Porto Alegre: Bookman, 2002.

KOTTER, J. P. Como liderar a mudança: por que os esforços de transformação fracassam. In: KOTTER, J. P. Gestão da Mudança. Rio de Janeiro: Elsevier, 2005. p. 9-26.

KOTTER, J. P. Oito Erros Fatais. Revista HSM Management, n. $11,1998$.

LERNER, M. A. A Gift Observed: Essays on Philanthropy and Civilization. Common Knowledge, 2000

MANDELll, P. et al. A Disciplina e a Arte da Gestão das Mudanças nas Organizações: Como Integrar Estratégias e Pessoas. Rio de Janeiro: Campus, 2003.

MATTAR, F. N. Pesquisa de Marketing: Edição Compacta. São Paulo: Atlas, 1996.

MEGGINSON, L. C.; MOSLEY, D. C.; PIETRI JUNOIR, P. H. Administração: conceitos e aplicações. São Paulo: Harper \& How do Brasil, 1986.

MlORANDO, R. F. Desenvolvimento e Aplicação de um Modelo de Avaliação de Rodovias Federais Concedidas: uma Abordagem Voltada aos Usuários. 2005. Dissertação (Mestrado em Engenharia de Produção)-Escola de Engenharia, Universidade Federal do Rio Grande do Sul, Porto Alegre, 2005.

PAULA, I. C.; RIBEIRO, J. L. D. A Proposal of a Reference Model for the Pharmaceutical PDP Management. Brazilian Journal of Operations \& Production Management, v. 4, n. 2, p. 05-32, 2007.

PEREIRA, E.; PEREZ, M. C. Aplicação do Modelo de Organizações Sociais e Contratos de Gestão: Resultados Alcançados. In: CONGRESO INTERNACIONAL DEL CLAD SOBRE LA REFORMA DEL ESTADO Y DE LA ADMINISTRACIÓN PÚBLICA, 7., 2002, Lisboa. Anais... Lisboa, 2002. p. 8-11. 
PRASAD, B. Concurrent Engineering Fundamentals: Integrated Product Development. New Jersey: Prentice Hall, 1997. v. 2 .

PROJECT MANAGEMENT INSTITUTE. Guia do Conjunto de Conhecimentos em Gerenciamento de Projetos. 4. ed. Pennsylvania: Project Management Institute, 2008.

ROMANO, L. N. Modelo de referência para o processo de desenvolvimento de máquinas agrícolas. 2003. Tese (Doutorado em Engenharia Mecânica) - Universidade Federal de Santa Catarina, Florianópolis, 2003.

ROZENFELD, $\mathrm{H}$. et al. Gestão de desenvolvimento de produtos: Uma referencia para a melhoria do processo. Editora Saraiva, 2006.

SALAMON, L. M.; ANHEIER, H. K. In Search of the Non-Profit Sector 1: the Question of Definitions. Voluntas - International Journal of Voluntary and Non-Profit Organisations, v. 13, n. 2, p. 125-152, 1992.

SAMARA, B. S.; BARROS, J. C. Pesquisa de Marketing: Conceitos e Metodologia. 3. ed. São Paulo: Pearson Prentice Hall, 2002.

SILVA, E. L.; MENEZES, E. M. Metodologia da pesquisa e elaboração de dissertação. Florianópolis: Universidade Federal de Santa Catarina, 2000.

TENÓRIO, F. G. Gestão de ONGs: Principais Funções Gerenciais. 2. ed. Niterói: Fundação Getúlio Vargas, 1998.
THIOLlENT, M. Pesquisa-Ação nas Organizações. São Paulo: Atlas, 1997.

TZORTZOPOULOS, P. The design and implementation of product development process models in construction companies Salford. 2004. Tese (Doutorado)-School of Construction and Property Management, University of Salford, 2004.

VALERIANO, D. L. Gerenciamento estratégico e administração por projetos. São Paulo: Makron Books, 2001.

VERZUH, E. Gestão de Projetos. 6. ed. Rio de Janeiro: Campus, 2000.

WEERAWARDENA, J.; MORT, G. S. Investigating social entrepreneurship: A multidimensional model. Journal of World Business, v. 41, n. 1, p. 21-35, 2006. http://dx.doi. org/10.1016/j.jwb.2005.09.001

XAVIER, C. M. S. Gerenciamento de projetos: Como definir e controlar o escopo do projeto. São Paulo: Saraiva, 2005.

XAVIER, C. M. S. et al. Metodologia de Gerenciamento de projetos - Methodware. Brasport, 2005.

\section{Agradecimentos}

Os autores agradecem à Capes e ao CNPq pela concessão de bolsas de pesquisa que viabilizaram a realização deste trabalho.

\title{
Identification of project opportunities in social organizations: development and case study
}

\begin{abstract}
This article presents the initiation processes of project management. An approach to the identification of opportunities and the preliminary definition of projects scope within social organizations was proposed. The proposal was structured in ten steps grouped into four macro-steps: (i) planning, (ii) information gathering, (iii) identification of opportunities, and (iv) preliminary definition of project scope. The approach was applied to a community organization, as a case study, generating six project opportunities. The findings showed that the presented approach provides a complete overview of the elements to be considered in the design of projects aimed at social organizations and it grants the engagement of the members of these organizations.
\end{abstract}

Keywords

Project management. Marketing research. Management change. Social organizations. 